\title{
Associação do Polimorfismo do Gene do Hormônio de Crescimento com a Caraterística Peso em Bovinos da Raça Nelore
}

\author{
Maria Marina Unanian1, Cristine Chaves Barreto², Alfredo Ribeiro de Freitas ${ }^{3}$, Célia Maria \\ Torres Cordeiro ${ }^{1}$, Luiz Antonio Josahkian ${ }^{4}$
}

\begin{abstract}
RESUMO - O polimorfismo do gene do hormônio de crescimento bovino (bGH) foi estudado em 211 bovinos machos da raça Nelore, puros de origem (PO), a fim de observar as frequiências genotípicas e alélicas, e a possível associação com a característica peso. Para alcançar este objetivo, foram considerados os pesos ao nascer, à desmama e mensais dos 10 aos 16 meses de idade, e calculados os ganhos de peso do nascimento à desmama e da desmama aos 16 meses. Foi coletado sangue para extração do DNA e análise dos sítios polimórficos (RFLP) oriundos da digestão com as endonucleases Msp I (bGH/Msp I, 891 pb), Hae III (bGH/Hae III, 441 pb) e Alu I (bGH/Alu I, $427 \mathrm{pb}$ ). Para cada polimorfismo foram encontrados dois alelos, ocorrendo predominância dos alelos D, F e A, respectivamente. Foi observado o efeito do genótipo AA do bGH/Alu I sobre o ganho de peso da desmama até 15 meses de idade e do genótipo DD do bGH/Msp I sobre os ganhos de peso da desmama aos 14 e 15 meses. Os resultados sugerem que os polimorfismos bGH/Alu I e bGH/Msp I constituem marcadores, em potencial, da característica ganho de peso em animais jovens.
\end{abstract}

Palavras-chave: bovinos, gene do hormônio de crescimento, pesos, raça Nelore

\section{Associations between Growth Hormone Gene Polymorphism and Weight Traits in Nellore Bovines}

\begin{abstract}
The polymorphism of the growth hormone gene (bGH) was studied in 211 Nellore pure breed bovine males to estimate the genotype and allelic frequencies and possible associations of the gene with weight traits. For this study, body weight data were collected at birth, weaning and monthly from 10 to 16 months of age. Additionally, weight gains from birth to weaning and weaning to 16 months of age were calculated. DNA was extracted from blood samples and the animals genotyped for Msp I (bGH/Msp I, $891 \mathrm{bp}$ ), Hae III (bGH/Hae III, 441 bp) and Alu I (bGH/Alu I, 427 bp) polymorphic sites. Every polymorphism presented two alleles. The predominant alleles were D, F and A, respectively. The effect of the bGH/Alu I AA genotype was observed on the weight gain from weaning to 15 months of age, and of the bGH/Msp I DD genotype from weaning to 14 and 15 months. The results suggest that bGH/Alu I and bGH/Msp I polymorphisms may be potential markers for the weight gain trait in young bulls.
\end{abstract}

Key Words: bovine, growth hormone gene, weight, Nellore breed

\section{Introdução}

Os marcadores de DNA tornaram-se, na última década, importantes para identificação de animais portadores de doenças genéticas e do parentesco, além de características de produção de interesse econômico. Em particular, as características de produção, pela sua importância, têm proporcionado vários estudos com a finalidade de oferecer, efetivamente, uma tecnologia molecular que, no futuro, permita selecionar animais mais produtivos com maior precisão.

Entre os marcadores de DNA, os chamados genes candidatos têm sido utilizados com este propósito, em função da sua ligação a compostos como hormônios de conhecida função fisiológica, fazendo parte desta categoria de marcadores o gene do hormônio de crescimento. Pelas atividades biológicas que o hormônio de crescimento exerce no organismo, incluindo desde a regulação do crescimento propriamente dito, função galactopoiética, gliconeogênese, ativação da lipólise, incorporação de aminoácidos nas proteínas dos músculos (GLUCKMAN et al., 1987) e, ainda, ativação de processos imunes envolvidos na resistência a doenças (ARKINS et al., 1993), acredita-se que o seu gene esteja associado a uma ou mais características de produção.

\footnotetext{
1 Pesquisadora da EMBRAPA - Cenargen, Parque Estação Biológica-PqEB, Final Av. W5 Norte, $70770-900$ Brasília, DF. E.mail: unanian@cenargen.embrapa.br

2 Bolsista ABCZ/FAZU, EMBRAPA - Cenargen, Parque Estação Biológica-PqEB, Final Av. W 5 Norte, $70770-900$ Brasília, DF

3 Pesquisador da EMBRAPA - CPPSE, Rod. Washington Luiz km 234, 13560-970 São Carlos, SP

4 Superintendente Técnico da ABCZ, Praça Vicente Rodrigues da Cunha 110, 38022-330 Uberaba, MG.
} 
A estrutura do gene do hormônio de crescimento bovino (bGH), descrita por WOYCHIK (1982) e GORDON et al. (1983), mostrou possuir alto grau de polimorfismo, sendo vários os sítios polimórficos encontrados (KIRKPATRIK, 1992; HOJ et al., 1993; LUCY et al., 1991; ZHANG et al., 1992 e 1993; e UNANIAN et al., 1994). Os estudos sobre a estrutura do bGH foram seguidos de pesquisas que procuraram relacionar os polimorfismos encontrados à produção (HOJ et al., 1993) e quantidade de gordura do leite (YAO et al., 1996), ao peso ao nascimento (ROCHA et al., 1992) e, ainda, à composição e qualidade de carcaça (TAYLOR et al., 1998).

O objetivo deste estudo foi procurar as possíveis associações dos polimorfismos do gene do hormônio de crescimento bovino com as características peso e ganho de peso, em animais da raça Nelore, com a finalidade de acrescentar informações que possam auxiliar na seleção deste animais.

\section{Material e Métodos}

O estudo foi realizado em 211 machos da raça Nelore, filhos de 22 touros, puros de origem (PO), criados a pasto e pertencentes a seis fazendas localizadas no Estado de São Paulo.

Os animais foram avaliados, mensalmente, quanto aos pesos dos 10 aos 16 meses de idade (P10, 11, 12, $13,14,15$ e 16), sendo considerados também os pesos ao nascer $(\mathrm{PN})$ e à desmama (PD) e calculados os ganhos de peso do nascimento à desmama (GPND), da desmama aos 12 (GPD12), 13 (GPD13), 14 (GPD14), 15 (GPD15) e 16 (GPD16) meses. Os pesos ao nascer e à desmama foram fornecidos pelas fazendas, sendo os demais obtidos por ocasião da coleta de dados.

Os animais deste experimento fizeram parte do estudo de precocidade reprodutiva, tendo apresentado a puberdade (concentração de 50 x $10^{6}$ espermatozóides/mL e motilidade acima de 10\%) dos 12 aos 16 meses. Dentro dessa faixa etária, em função do aparecimento da puberdade e conseqüente utilização nas propriedades, os animais foram retirados do experimento.

Para extração de DNA, de cada animal, foi coletada uma amostra de cerca $20 \mathrm{~mL}$ de sangue em tubos a vácuo com EDTA $\mathrm{K}_{3}$. $\mathrm{O}$ sangue foi mantido refrigerado e o seu processamento ocorreu, no máximo, 5 dias após a coleta.

O DNA foi extraído a partir da camada de leucócitos obtida por centrifugação do sangue a $3000 \mathrm{rpm}$, durante 10 minutos, $\mathrm{a} 20^{\circ} \mathrm{C}$. Esta camada foi submetida a várias lavagens por centrifugação (4000 rpm, 10 minutos, a $20^{\circ} \mathrm{C}$ ) com tampão contendo $0,14 \mathrm{M} \mathrm{NH}_{4} \mathrm{Cl}$, e 0,017 M Tris- $\mathrm{HCl}$, até se obter um sobrenadante limpo de hemoglobina. O pelet foi resuspendido em $3 \mathrm{~mL}$ de tampão para digestão $(0,01 \mathrm{M}$ Tris- $\mathrm{HCl}, 0,4 \mathrm{M}$ $\mathrm{NaCl}, 2 \%$ SDS, 0,05 M EDTA), adicionado Proteinase $\mathrm{K}(500 \mu \mathrm{g})$, e digerido a $55^{\circ} \mathrm{C}$ durante a noite. $\mathrm{Em}$ seguida, foi acrescido RNase A $(100 \mu \mathrm{g})$ durante uma hora. Após esta etapa, houve adição de $1 \mathrm{~mL}$ de $\mathrm{NaCl}$ $5 \mathrm{M}$ às amostras, seguida de homogeneização e centrifugação $\left(4000 \mathrm{rpm}, 10\right.$ minutos, a $\left.20^{\circ} \mathrm{C}\right)$. A precipitação do DNA foi realizada no sobrenadante com etanol 100\%. Em seguida, o DNA foi seco sob vácuo e o pelet, resuspendido com água bidestilada. Após a diluição, o DNA foi quantificado por espectrofotometria a 260 e $280 \mathrm{~nm}$ para verificar a concentração e o grau de pureza pela proporção DNA:proteína.

O DNA assim obtido foi amplificado por meio da reação em cadeia da polimerase (PCR), de acordo com ZHANG et al. (1992, 1993), UNANIAN et al. (1994) e LUCY et al. (1991). Para cada reação, foram utilizados $100 \mathrm{ng}$ DNA, 1 x Taq Buffer (100 mM Tris- $\mathrm{HCl}, 500 \mathrm{mM} \mathrm{KCl,} 15 \mathrm{mM} \mathrm{MgCl}_{2}$, $0,01 \%$ gelatina e $1 \%$ Triton $\mathrm{X}-100 ; \mathrm{pH} 9,0), 1,5 \mathrm{mM}$ $\mathrm{MgCl}_{2}, 200 \mu \mathrm{M}$ dNTP, $2 \mathrm{U}$ Taq DNA polimerase, $0,8 \mathrm{mM}$ de cada oligonucleotideo, num volume final de $50 \mu \mathrm{L}$. A reação ocorreu em um termociclador, em que o programa de amplificação constou de um ciclo $97^{\circ} \mathrm{C} / 1,5$ minuto, $62^{\circ} \mathrm{C} / 1$ minuto e $72^{\circ} \mathrm{C} / 1$ minuto; 48 ciclos de um minuto cada nas temperaturas de 94, 62 e $72^{\circ} \mathrm{C}$, finalizando com um ciclo de $72^{\circ} \mathrm{C} / 4$ minutos. A seqüência dos oligonucleotídeos utilizados na PCR está apresentada na Tabela 1.

Os produtos de amplificação $(10 \mu \mathrm{L})$ foram digeridos, separadamente, com as endonucleases Msp I (15 U), Hae III (10 U) e Alu I (4 U), a $37^{\circ} \mathrm{C}$, durante a noite. Os fragmentos resultantes (RFLP) foram identificados por eletroforese em gel de agarose (3\%) acrescido de $0,5 \mu \mathrm{L}$ de brometo de etídio $(10 \mathrm{mg} / \mathrm{mL})$.

O produto da PCR utilizado para a digestão com a endonucealse Msp I apresentou 891 pares de bases (pb) sendo $177 \mathrm{pb}$ do intron 2, $117 \mathrm{pb}$ do exon III, $227 \mathrm{pb}$ do intron 3, $162 \mathrm{pb}$ do exon IV e $208 \mathrm{pb}$ do intron 4, conforme descrito por ZHANG et al. (1993). Para a digestão com a endonuclease Hae III, amplificou-se um fragmento de $441 \mathrm{pb}$ contendo o exon $\mathrm{V}$ e a região flanqueadora 3' (UNANIAN et al., 1994) e, para Alu I, um fragmento de $427 \mathrm{pb}$ constituído de $55 \mathrm{pb}$ do exon IV (3'região), 273 pb do intron 4 e 99 pb do exon V 
1382 Rev. bras. zootec.

Tabela 1 - Seqüências dos oligonucleotídeos utilizados na PCR do gene do hormônio de crescimento bovino em machos da raça Nelore, PO, e respectivos autores

Table 1 - Oligonucleotides sequences used for PCR of bovine growth hormone gene in Nellore purebred males and respectives authors

\begin{tabular}{llc}
\hline $\begin{array}{l}\text { Polimorfismo } \\
\text { Polymorphism }\end{array}$ & $\begin{array}{c}\text { Seqüência } \\
\text { Sequence }\end{array}$ & $\begin{array}{c}\text { Autor } \\
\text { Author }\end{array}$ \\
\hline bGH/Msp I & 5'-ATC CAC ACC CCC TCC ACA CAG T -3' & ZHANGet al. (1993) \\
bGH/Hae III & 5'-CAT TTT CCA CCC TCC CCT ACA G -3' & UNANIAN et al. (1994) \\
bGH/Alu I & 5'-ACG CGC TGC TCA AGA AC-3' & \\
& 5'-GGC TGG AAC TAA GAA CC-3' & LUCY et al. (1992) \\
\hline
\end{tabular}

(5'região) (ZHANG et al., 1992) do gene do homônimo de crescimento, conforme a seqüência descrita por GORDON et al. (1983).

Para verificar a influência dos genótipos dos fragmentos polimórficos do gene do hormônio de crescimento bovino sobre o desenvolvimento do animal, as características PN, PD e ganhos de peso do nascimento à desmama (GPND), da desmama aos 12 (GPD 12), 13 (GPD 13), 14 (GPD 14), 15 (GPD 15) e 16 (GPD 16) meses de idade foram analisadas por meio de um modelo matemático e uso do procedimento GLM do programa SAS (1993), que incluiu, além do efeito médio, os efeitos de fazenda, grupo contemporâneo, touro (fazenda) e genótipos. Para todas as características, o PN foi utilizado como covariável no modelo.

A influência dos genótipos dos polimorfismos do gene do hormônio de crescimento bovino sobre o desenvolvimento do animal foi também avaliada por meio do modelo Bertalanffy (FREITAS et al., 1998) para estimar o crescimento do animal em função da idade, dado pelo modelo $\mathrm{y}_{\mathrm{t}}=\mathrm{A}\left(1-\mathrm{Be} \mathrm{e}^{-\mathrm{kt}}\right)^{3}$, em que $\mathrm{y}_{\mathrm{t}}$ representa o peso corporal em $\mathrm{kg}$ no instante $\mathrm{t}$, expresso em dias após o nascimento; A, o peso estimado às últimas pesagens; $\mathrm{B}$, a constante de integração sem interpretabilidade biológica; e K, a taxa de maturidade pós-natal, em que valores altos indicam maturidade precoce e valores baixos maturidade retardada. Para o ajuste do modelo, os dados de pesos foram corrigidos apenas para os efeitos fixos de fazenda e grupo contemporâneo. As estimativas dos parâmetros deste modelo foram obtidas por meio do procedimento NLIN do SAS (SAS, 1993).

\section{Resultados e Discussão}

Os polimorfismos identificados com as endonucleases Msp I, Hae III e Alu I apresentaram dois alelos cada um, conforme descrito por ZHANG et al. (1992 e 1993) e UNANIAN et al. (1994).

Para o bGH/Msp I, foi encontrado o alelo C com quatro fragmentos de restrição $(526,193,109$ e 63 pares de bases) e o D com três $(635,193$ e 63 pares de bases), oriundo pela perda de um sítio de restrição no $3^{\circ}$ intron. $\mathrm{O}$ bGH/Hae III apresentou três fragmentos para o alelo $\mathrm{E}(268,102 \mathrm{e} 71 \mathrm{pb})$ e quatro para o F $(268,102$, 71 e $50 \mathrm{pb})$. No bGH/Alu I, resultaram três fragmentos no alelo A $(264,147$ e 16 pb) e quatro no alelo B $(264,96,51$ e 16 pb). Esta última sequiência revelou que, na posição +1492 do bGH, houve substituição da citosina pela guanina abolindo o sítio de restrição para a enzima Alu I. Isto levou à mudança da leucina pelo aminoácido valina na posição 127 da proteína do bGH (ZHANG et al., 1992).

A freqüência genotípica e alélica de cada polimorfismo do gene do hormônio de crescimento bovino está apresentada na Tabela 2 .

A freqüência observada para o alelo $\mathrm{D}$ e $\mathrm{C}$, respectivamente 0,85 e 0,15 , para o polimorfismo bGH/Msp I foi semelhante à descrita por MITRA et al. (1995), em animais zebuinos da raça Sahiwal, de 0,86 e 0,14 , e BORGES (1997) de 0,88 e 0,12 , e RODRIGUES et al. (1998), de 0,844 e 0,156, em animais da raça Nelore, sendo diferente da observada por ARAVINDAKSHAN et al. (1997) de 0,93 e 0,07 em animais da raça Ongole. Estes resultados mostraram que existe variação na freqüência alélica entre raças, conforme observação de MOODY et al. (1996).

A frequiência alélica obtida nos animais Nelore, neste estudo, indica a predominância do alelo D, como também observado por BORGES (1997). A predominância deste alelo (D) na população estudada pode ter sido por deriva genética como sugerido por BORGES (1997), uma vez que nestes rebanhos é praticada a inseminação artificial, e a escolha de touros é realizada em um número finito de reprodutores considerados geneticamente superiores. 
A freqüência alélica do bGH/Alu I, 0,92 e 0,08 respectivamente, mostrou a predominância do alelo A, não tendo sido encontrados animais homozigotos para o alelo B (Tabela 2). A freqüência dos alelos A e $\mathrm{B}$ foi semelhante à descrita por MITRA et al. (1995) em animais da raça Sahiwal, de 0,94 e 0,04, e diferente de RODRIGUES et al. (1997), que encontraram somente o alelo A, em animais da raça Nelore. A predominância do alelo Aem populações zebuínas foi ainda descrita por ROSA et al. (1996).

Ao contrário do observado no polimorfismo bGH/Msp I, em que um dos alelos (D) aparece como predominante nos zebuínos e, segundo BORGES (1997), o alelo C nos taurinos, o alelo A do bGH/Alu I predomina tanto nos zebuínos como nos taurinos. A frequiência do alelo A obtida nos zebuinos neste trabalho foi semelhante à descrita por ZHANG et al. (1993) e SCHLEE et al. (1994) em animais Bos taurus das raças de corte Angus, Simmental, Hereford, Limousin, Wagyu e Gelbvieh.

O polimorfismo bGH/Hae III apresentou predominância do alelo $\mathrm{F}$ (Tabela 2); além disso, não foram encontrados animais homozigotos para o alelo E. Os mesmos resultados foram obtidos por UNANIAN et al. (1994) em animais Brahman, não tendo sido encontrados outros relatos deste polimorfismo.

A predominância alélica (alelos D, Fe A) observada nos polimorfismos bGH Msp I, bGH Hae III e bGH Alu I, possivelmente, constitui característica dos animais Bos indicus. No entanto, para que isto seja confirmado, é necessário que as demais raças indianas apresentem freqüência alélica semelhante, devendo-se considerar também o tamanho amostral. Este estudo utilizando uma amostra de 211 animais maior que a encontrada nas literaturas consultadas, proporcionou resultados diferenciados dos que descreveram os alelos D e A, na raça Nelore, como fixados na população (ROSA et al., 1996; RODRIGUES et al., 1998). Em vista destes resultados é possível que, analisando número maior de animais, ocorra aumento na freqüência dos alelos $\mathrm{C}, \mathrm{E}$ e B, principalmente considerando a origem dos animais Nelore de seis linhagens oficialmente catalogadas (MAGNABOSCO et al., 1997).

Os resultados da associação entre os polimorfismos do gene do hormônio de crescimento estudados e as características quantitativas medidas neste estudo estão apresentados nas Tabelas 3 e 4 e Figura 1. Conforme observado na Tabela 3 , não houve efeito significante dos genótipos sobre o PN, como também relatado por BORGES (1997), em animais da raça Nelore, e TAYLOR et al. (1998), em Brahman e Hereford. Apenas ROCHA et al. (1992) observaram diferenças nos PN, em função dos genótipos maternos, em animais da raça Brahman.

A Figura 1 apresenta os intervalos de confiança com $95 \%$ de probabilidade das estimativas dos pesos, em função da idade obtidas por meio do modelo Bertalanaffy. Com base nestas estimativas, não se observaram diferenças significativas entre os homo e heterozigotos em nenhum dos três polimorfismos estudados. No entanto, verificou-se que, em torno de 400 e 300 dias de idade, houve tendência de se detectar diferença entre os homo e heterozigotos em relação aos polimorfismos bGH/Msp Ie bGH/Alu I, respectivamente. Possivelmente, com o estudo de maior amostra de

Tabela 2 - Freqüências genotípicas e alélicas do polimorfismo do gene do hormônio de crescimento bovino em machos da raça Nelore, PO

Table 2 - Genotype and allele frequencies of bovine growth hormone gene polymorphism in purebred Nellore males

\begin{tabular}{lccccc}
\hline $\begin{array}{l}\text { Polimorfismo } \\
\text { Polymorphism }\end{array}$ & \multicolumn{2}{c}{$\begin{array}{c}\text { Freqüências genotípicas (\%) } \\
\text { Genotype frequencies }(\%)\end{array}$} & \multicolumn{2}{c}{$\begin{array}{c}\text { Freqüência alélica (\%) } \\
\text { Allelefrequencies (\%) }\end{array}$} \\
\hline bGH/Msp I & $\mathrm{CC}$ & $\mathrm{CD}$ & $\mathrm{DD}$ & $\mathrm{C}$ & $\mathrm{D}$ \\
& $(\mathrm{n}=3)$ & $(\mathrm{n}=56)$ & $(\mathrm{n}=152)$ & $(\mathrm{n}=31)$ & $(\mathrm{n}=180)$ \\
& 1,42 & 26,54 & 72,04 & 0,15 & 0,85 \\
bGH/Hae III & $\mathrm{FF}$ & $\mathrm{EF}$ & $\mathrm{EE}$ & $\mathrm{F}$ & $\mathrm{E}$ \\
& $(\mathrm{n}=182)$ & $(\mathrm{n}=8)$ & $(\mathrm{n}=0)$ & $(\mathrm{n}=186)$ & $(\mathrm{n}=4)$ \\
bGH/Alu I & 95,79 & 4,21 & 0 & 0,98 & 0,02 \\
& $\mathrm{AA}$ & $\mathrm{AB}$ & $\mathrm{BB}$ & $\mathrm{A}$ & $\mathrm{B}$ \\
& $(\mathrm{n}=160)$ & $(\mathrm{n}=29)$ & $(\mathrm{n}=0)$ & $(\mathrm{n}=175)$ & $(\mathrm{n}=15)$ \\
& 84,66 & 15,34 & 0 & 0,92 & 0,08
\end{tabular}

$\mathrm{n}=$ número de animais.

$n=$ number of animal. 
1384 Rev. bras. zootec.
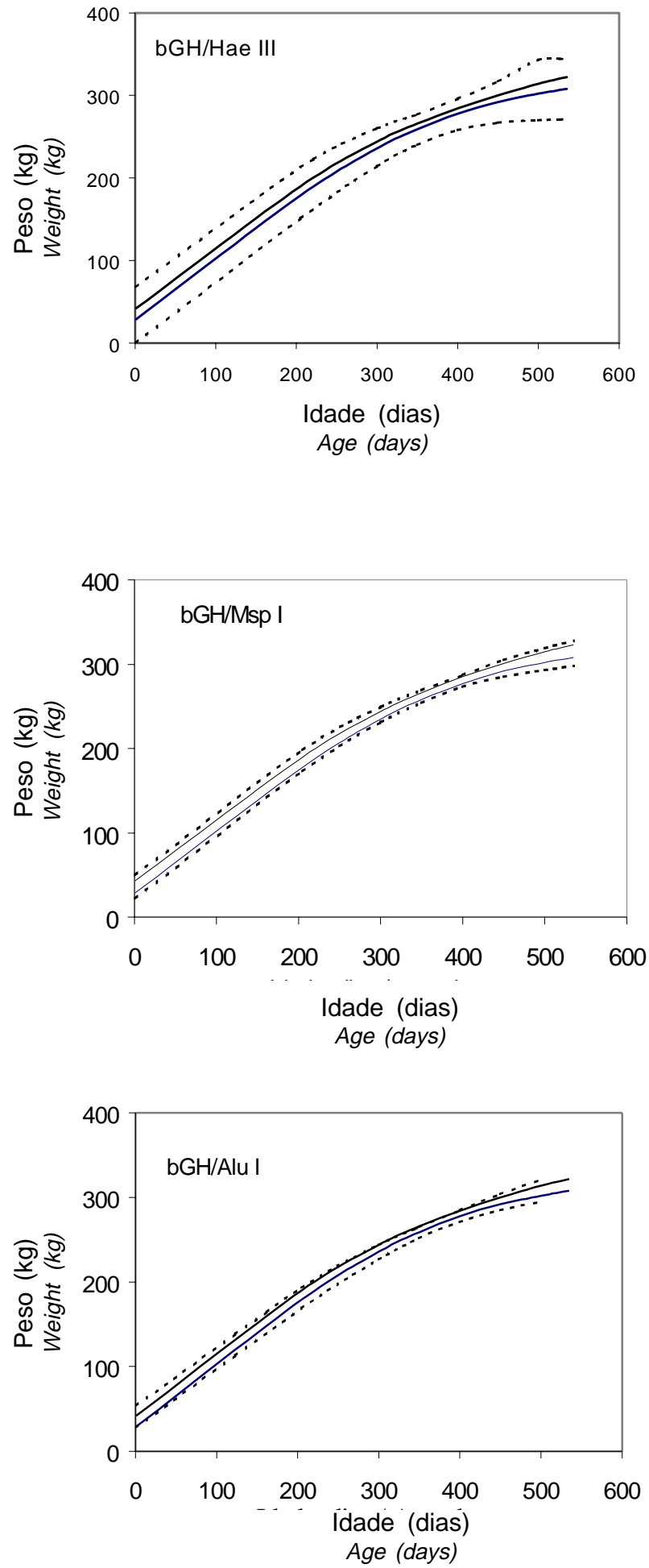

Figura 1 - Efeito dos genótipos do gene hormônio de crescimento bovino sobre o peso corporal, em machos da raça Nelore, PO (intervalo de confiança com $95 \%$ de probabilidade; - = limite inferior e superior de homozigoto; $\cdot . \cdot \cdot=$ limite inferior e superior de heterozigoto)

Figure 1 - Effect of bovine growth hormone genotype polymorphisms on the body weight in Nellore pure breed males (confidence interval of $95 \%$ of probability; - - = lower and upper limits of homozygotes; ..... = lower and upper limits of heterozygotes).
Tabela 3 - Médias ( \pm EP) dos pesos ao nascer e à desmama em função dos genótipos do gene do hormônio de crescimento bovino, em machos da raça Nelore, $\mathrm{PO}$

Table 3 - Means ( \pm SE) for body weights at birth time and at weaning time in function of bovine growth hormone gene genotypes in Nellore pure breed males

\begin{tabular}{llcc}
\hline $\begin{array}{l}\text { Polimorfismo/Genótipo } \\
\text { Polymorphism/Genotype }\end{array}$ & \multicolumn{2}{c}{$\begin{array}{c}\text { Característica peso (kg) } \\
\text { Weight characteristic }(\mathrm{kg})\end{array}$} \\
\cline { 3 - 4 } & & $\begin{array}{c}\text { Nascimento } \\
\text { At birth } \\
(\mathrm{n}=179)\end{array}$ & $\begin{array}{c}\text { Desmama } \\
\text { At weaning } \\
(\mathrm{n}=157)\end{array}$ \\
\hline bGH/Msp I & CC & $33,33 \pm 0,66$ & $203,00 \pm 11,37$ \\
& CD & $32,64 \pm 0,49$ & $195,55 \pm 4,74$ \\
bGH/Hae III & DD & $32,21 \pm 0,27$ & $197,61 \pm 2,94$ \\
& FF & $32,34 \pm 0,24$ & $197,75 \pm 2,55$ \\
bGH/Alu I & EF & $32,62 \pm 0,82$ & $183,67 \pm 7,74$ \\
& AA & $32,05 \pm 0,24$ & $195,13 \pm 2,60$ \\
& AB & $34,07 \pm 0,71$ & $215,62 \pm 5,94$ \\
\hline
\end{tabular}

$\mathrm{n}=$ número de animais.

$n=$ number of animals.

animais, essas tendências observadas poderiam resultar em diferenças significativas.

Os pesos dos animais em relação a bGH/Msp I e bGH/Alu I foram mais homogêneos, quando comparados aos do polimorfismo bGH/Hae III, uma vez que os intervalos de confiança foram mais estreitos em todo o período estudado. No entanto, devido à maior variabilidade observada nos animais heterozigotos, ou seja, intervalos de confiança maiores, independentemente de período e polimorfismo, há probabilidade de detectar animais heterozigotos com pesos significativamente superiores aos homozigotos, quanto à associação do polimorfismo do gene do hormônio de crescimento com a característica peso em bovinos da raça Nelore.

Levando em consideração a influência do hormônio de crescimento sobre o desenvolvimento dos tecidos, é provável que o seu gene esteja relacionado à característica ganho de peso. Apesar do número relativamente pequeno de animais, foi observado que, a partir dos 12 e 13 meses de idade, mesmo quando os dados não mostraram diferenças significativas, o ganho de peso esteve relacionado aos polimorfismos bGH/Alu I e bGH/Msp I, sendo que animais portadores do genótipo AA e DD ganharam, em média, mais peso que os demais (Tabela 4), resultando em incremento de 7,1 e 4,6\%, respectivamente. Considerando-se a freqüência dos genótipos AA e DD na população estudada (Tabela 2), a sua contribuição para o ganho de peso foi de 85 e $72 \%$, respec- 
Tabela 4 - Médias ( \pm EP) dos ganhos de peso do nascimento à desmama e da desmama até 16 meses de idade, em função dos genótipos do gene do hormônio de crescimento bovino, em machos da raça Nelore, PO

Table 4 - Means ( \pm SE) for body weight gains from birth to weaning and from weaning to 16 months of age, in fuction of the genotypes of bovine growth hormone gene in Nellore pure breed males

\begin{tabular}{|c|c|c|c|c|c|c|c|c|c|c|}
\hline \multicolumn{2}{|c|}{$\begin{array}{l}\text { Polimorfismo/Genótipo } \\
\text { Polymorphism/Genotype }\end{array}$} & \multicolumn{9}{|c|}{$\begin{array}{c}\text { Característica ganho de peso (kg/dia) } \\
\text { Weight gain characteristic }(\mathrm{kg} / \text { day })\end{array}$} \\
\hline & & $\begin{array}{l}\text { GPND } \\
(\mathrm{n}=157)\end{array}$ & $\begin{array}{l}\text { GPD 12 } \\
(\mathrm{n}=128)\end{array}$ & & $\begin{array}{l}\mathrm{SPD} 13 \\
\mathrm{a}=110)\end{array}$ & & $\begin{array}{l}\text { PD14 } \\
=101)\end{array}$ & $\begin{array}{l}\text { GPD1 } \\
(\mathrm{n}=83\end{array}$ & & $\begin{array}{l}\text { GPD16 } \\
(\mathrm{n}=34)\end{array}$ \\
\hline \multirow[t]{3}{*}{ bGH/Msp I } & $\mathrm{CC}$ & 11,99 & $=4,01$ & 76,50 & $\pm 14,55^{\mathrm{a}}$ & 76 , & $\pm 14,0$ & $104,00 \pm$ & 37,11 & \\
\hline & $\mathrm{CD}$ & $163,45 \pm 4,63$ & $20 \pm 7,60$ & 77,46 & $\pm 12,42$ & 90,64 & $\pm 11,09^{\mathrm{a}}$ & $107,33 \pm$ & $=12,99^{a}$ & 119,1 \\
\hline & DD & $165,61 \pm 2,92$ & $57,92 \pm 4,03$ & 76,42 & 5,45 & 106,72 & $\pm 5,71^{b}$ & $125,48 \pm$ & $5,86^{\mathrm{b}}$ & $122,48 \pm 11,46$ \\
\hline \multirow[t]{2}{*}{ bGH/Hae III } & $\mathrm{FF}$ & $165,70 \pm 2,50$ & $57,92 \pm 3,57$ & 76,32 & 5,15 & 101,99 & $\pm \quad 5,15$ & $117,57 \pm$ & 5,33 & $120,00 \pm 11,13$ \\
\hline & $\mathrm{EF}$ & $151,67 \pm 8,02$ & $64,50 \pm 19,16$ & 84,60 & $\pm 24,77$ & 104,50 & $\pm 25,24$ & $161,75 \pm$ & 40,25 & \\
\hline \multirow[t]{2}{*}{ bGH/Alu I } & AA & $163,23 \pm 2,58$ & $59,66 \pm 3,73^{\mathrm{a}}$ & 79,93 & $\pm 5,37^{\mathrm{a}}$ & 106,35 & $\pm 5,10^{\mathrm{a}}$ & $121,43 \pm$ & 5,57 & $125,78 \pm 12,82$ \\
\hline & $\mathrm{AB}$ & $182,25 \pm 6,07$ & $46,53 \pm 9,85^{b}$ & 47,27 & $\pm 10,27^{b}$ & 59,11 & $\pm 16,87^{b}$ & $97,50 \pm$ & $=24,06$ & $100,14 \pm 21,71$ \\
\hline
\end{tabular}

Médias, na coluna, acompanhadas de letras diferentes são significantes a $5 \%$ pelo teste $\mathrm{F}$.

$\mathrm{n} \quad=$ número de animais.

GPND $\quad=$ ganho de peso do nascimento à desmama.

GPD 12 até 16 = ganho de peso da desmama até 16 meses de idade.

Means, within a column, followed by different letters are significant at $5 \%$ by $F$ test.

= number of animals.

GPND= weight gain from birth to weaning

GPD 12 to 16 = weight gain from weaning to 16 months of age.

tivamente, mostrando a importância dos animais portadores destes genótipos para a seleção e a facilidade de praticar a seleção desta característica nestes rebanhos. A elevada frequiência genotípica verificada neste estudo poderia ser oriunda da seleção praticada nestas fazendas com base nos DEPs. Ainda, como o efeito do polimorfismo bGH/Msp I e bGH/Alu I foi observado apenas pela comparação entre os animais homozigotos, dos alelos mais freqüentes, e os heterozigotos sempre em número menor, devido ao tamanho da amostra, é possível que o efeito observado tenha sido maior. No entanto, para aceitar ou rejeitar esta hipótese, é necessário aumentar o tamanho da amostra.

A associação significativa do polimorfismo bGH/Msp I com o ganho de peso pós-desmama, neste trabalho, ocorreu nos animais homozigotos para o alelo D, e não nos heterozigotos, como observado por BORGES (1997) em animais da raça Nelore.

O polimorfismo do bGH/Hae III não apresentou associação com os ganhos de peso considerados neste estudo. Este polimorfismo tem sido associado, por TAYLOR et al. (1998), à qualidade de carcaça (porcentagem de ácidos graxos), característica não estimada neste trabalho. A falta de associação, provavelmente, ocorreu em função do tamanho da amostra.

Quanto ao polimorfismo bGH/Alu I, a associação com o ganho de peso ocorreu nos animais homozigotos AA, da desmama aos 12, 13 e 14 meses de idade (Tabela 4), que ganharam mais peso $(\mathrm{P}<0,05)$ do que os AB. Estes resultados foram diferentes dos apresentados por SCHLEE et al. (1994), em animais da raça Simmental, em que os melhores animais foram heterozigotos, seguidos dos homozigotos para o alelo A.

\section{Conclusões}

Os polimorfismos bGH/Alu I e bGH/Msp I do gene do hormônio de crescimento constituem potenciais marcadores para a característica ganho de peso em bovinos machos da raça Nelore, puros de origem (PO).

No entanto, para confirmação dos resultados obtidos, é necessário que se aumente o tamanho da amostra.

\section{Agradecimento}

À Associação Brasileira de Criadores de Zebu (ABCZ), à Faculdade de Agronomia e Zootecnia de Uberaba (FAZU) e aos pecuaristas, pelo apoio no desenvolvimento deste trabalho.

\section{Referências Bibliográficas}

ARAVINDAKSHAN, T.V., NAINAR, A.M., RAMADASS, P. et al. 1997. Genetic polymorphism within the growth hormone gene of cattle and buffalo (Bubalus bubalis) detected by polymerase chain reaction and endonuclease. Int. J. Anim. Sci., 12(1):5-8. 
1386 Rev. bras. zootec.

ARKINS, S., DANTZER, R., KELLEY, K.W. 1993. Somatolactogens, somatomedins, and immunity. J. Dairy Sci., 76:2437-2442.

BORGES, M. Marcadores moleculares seus efeitos sobre características quantitativas de bovinos de corte. Uberaba, MG: UFU, 1997. 119p. Dissertação (Mestrado em Genética e Bioquímica)-Universidade Federal de Uberlândia, 1997.

FREITAS, A.R., ALENCAR, M.M., SILVA, A.S. 1998. Ajuste de modelos não-lineares em bovinos de corte. I. Padrão da população. In: REUNIÃO ANUAL DA SBZ, 35, 1998, Botucatu. Anais...Botucatu: FMVZ-UNESP, 1998. p.341-343.

GLUCKMAN, P.D., BREIER, B.H., DAVIS, S.R. 1987. Physiology of the somatotropic axis with particular reference to the ruminant. J. Dairy Sci., 70:442-466.

GORDON, D.F., QUICK, D.P., ERWIN, R.C. et al. 1983. Nucleotide sequence of the bovine growth hormone chromosomal gene. Mol. Cell. Endocrinol., 33:81-95.

HOJ, S., FREDHOLM, M., LARSEN, N.J. et al. 1993. Growth hormone gene polymorphism associated with selection or milk fat production in lines of cattle. Anim. Genet., 24:91-96.

KIRKPATRIC, B.W. 1992. Detection of a three-allele single strand conformation polymorphism (SSCP) in the fourth intron of the bovine growth hormone gene. Anim. Genet., 23:179-181.

LUCY, M.C., HAUSER, S.D., EPPARD, P.J. et al. 1991. Genetic polymorphism within the bovine somatotropin (bST) gene detected by polymerase chain reaction and endonuclease digestion. J. Dairy Sci., 74:284 (Suppl. 1).

MAGNABOSCO, C.U., CORDEIRO, C.M.T., TROVO, J.B.F. et al. 1997. Catálogo de linhagens do germoplasma zebuíno: raça Nelore. Brasília, DF: Cenargen/ABCZ. 52p.

MITRA, A., SCHLEE, P., BALAKRISHNAN, C.R. et al. 1995. Polymorphisms at growth-hormone and prolactin loci in Indian cattle and buffalo. J. Anim. Breed. Genet., 11:71-74.

MOODY, D.E., POMP, D., NEWMAN, S. et al. 1996. Characterization of DNA polymorphism in three populations of Hereford cattle and their associations with growth and maternal EPD in line 1 Herefords. J. Anim. Sci., 74:1784-1793.

ROCHA, J.L., BAKER, J.F., WOMACK, J.E. et al. 1992. Statistical associations between restriction fragment length polymorphisms and quantitative traits in beef cattle. J. Anim. Sci., 70:3360- 3370.

RODRIGUES, C.V., GUIMARÃES, S.E.F., PINHEIRO, L.E.L. 1997. Freqüências alélicas das variantes do hormônio de crescimento bovino por análise de polimorfismo de tamanho de fragmento de restrição (RFLP) em raças de corte. Rev.
Bras. Reprod. Anim., 21(2):189-192.

RODRIGUES, C.V., PEREIRA, J.C.C., RAZOOK, A.G. et al. 1998. Distribuição de variantes intragênicas do hormônio de crescimento bovino em touros Nelore. In: REUNIÃO ANUAL DA SBZ, 35, 1998, Botucatu. Anais... Botucatu: FMVZUNESP, 1998, p.264-266.

ROSA, A.J.M., REGITANO, L.C.A., MERZEL, M. et al. Polymorphism of growth hormone, microsatellite IGF-I and association with feedlot performance in Nellore cattle. In: CONGRESSO BRASILEIRO DE GENÉTICA, 42, 1996, Caxambú. Anais... Caxambú: SBG, 1996. p.298.

SAS. User's Guide, Version 6, Cary, NC: SAS Institute Inc., 1993.

SCHLEE, P., GRAML, R., ROTTMANN, O. et al. 1994. Influence of growth-hormone genotypes on breeding values of Simmental bulls. J. Anim. Breed. Genet., 111:253-256.

TAYLOR, J.F., COUTINHO, L.L., HERRING, K.L. et al. 1998. Candidate gene analysis of GH1 for effects on growth and carcass composition of cattle. Anim. Genet., 29:194-201.

UNANIAN, M.M., DeNISE, S.K., ZHANG, H.M. et al. 1994. Rapid communication: polymerase chain reaction-restriction fragment length polymorphism in the bovine growth hormone gene. J. Anim. Sci., 72:2203.

WOYCHIK, R.P., CAMPER, S.A., LYONS, R.H. et al. 1982. Cloning and nucleotide sequencing of the bovine growth hormone gene. Nucleic Acid Res., 10 (22):7197-7210.

YAO, J., AGGREY, S.E., ZADWORNY, D. et al. 1996. Sequence variations in the bovine growth hormone gene characterized by single-strand conformation polymorphism (SSCP) analysis and their association with milk production traits in Holsteins. Genetics, 144:1809-1816.

ZHANG, H.M., BROWN, D.R., DeNISE, S.K.et al. 1992. Nucleotide sequence determination of a bovine somatotropin allele. Anim. Genet., 23:578.

ZHANG, H.M., BROWN, D.R., DeNISE, S.K. et al. 1993. Rapid communication: polymerase chain reaction-restriction fragment length polymorphism analysis of the bovine somatotropin gene. J. Anim. Sci., 71:2276.

Recebido em: 19/08/99

Aceito em: 05/03/00 